\title{
Stereotactic body radiotherapy versus conventional/moderate fractionated radiation therapy with androgen deprivation therapy for unfavorable risk prostate cancer
}

Sagar A. Patel ${ }^{1 *}$ (D) Jeffrey M. Switchenko², Ben Fischer-Valuck', Chao Zhang ${ }^{2}$, Brent S. Rose ${ }^{3}$, Ronald C. Chen ${ }^{4}$, Ashesh B. Jani ${ }^{1}$ and Trevor J. Royce ${ }^{5}$

\begin{abstract}
Background: Ultrahypofractionation using stereotactic body radiotherapy (SBRT) is an increasingly utilized technique for men with prostate cancer (PC). The comparative efficacy of SBRT plus androgen deprivation therapy (ADT) compared to fractionated radiotherapy (EBRT) plus ADT in higher-risk prostate cancer is unknown.

Methods: Men $>40$ years old with localized PC treated with external beam radiation and concomitant ADT for curative intent between 2004 and 2016 were analyzed from the National Cancer Database. Patients who lacked ADT or risk stratification data were excluded. 558 men treated with SBRT versus 40,797 men treated with conventional or moderately hypofractionated EBRT were included. Patients were stratified by unfavorable intermediate (UIR) and high (HR) risk using NCCN criteria. Kaplan Meier and Cox proportional hazards were used to compare overall survival (OS) between RT modality, adjusting for age, race, and comorbidity index.

Results: With a median follow up of 74 months, there was no difference in estimated 6-year OS between men treated with SBRT versus EBRT regardless of risk group. On multivariable analysis, there was no difference in risk of death for men treated with SBRT compared to EBRT (UIR: adjusted HR 1.09, 95\% Cl 0.68-1.74, $p=.72$; HR: adjusted HR $0.93,95 \% \mathrm{Cl} 0.76-1.14, p=.51)$. On sensitivity analyses, when confining the cohort to men treated with NCCNpreferred dose fractionations, with no comorbidities, or $<65$ years old, there remained no survival difference between treatment groups for both UIR and HR.

(Continued on next page)
\end{abstract}

\footnotetext{
* Correspondence: sagar.patel@emory.edu

Meeting Presentation: Abstract accepted for presentation at the American

Society of Clinical Oncology Genitourinary Cancers Symposium (February 13-

15 2020, San Francisco)

'Department of Radiation Oncology, Winship Cancer Institute, Emory

University, Atlanta, GA, USA

Full list of author information is available at the end of the article
}

C C The Author(s). 2020 Open Access This article is licensed under a Creative Commons Attribution 4.0 International License, which permits use, sharing, adaptation, distribution and reproduction in any medium or format, as long as you give appropriate credit to the original author(s) and the source, provide a link to the Creative Commons licence, and indicate if changes were made. The images or other third party material in this article are included in the article's Creative Commons licence, unless indicated otherwise in a credit line to the material. If material is not included in the article's Creative Commons licence and your intended use is not permitted by statutory regulation or exceeds the permitted use, you will need to obtain permission directly from the copyright holder. To view a copy of this licence, visit http://creativecommons.org/licenses/by/4.0/. The Creative Commons Public Domain Dedication waiver (http://creativecommons.org/publicdomain/zero/1.0/) applies to the data made available in this article, unless otherwise stated in a credit line to the data. 


\begin{abstract}
(Continued from previous page)
Conclusion: Within study limitations, we found no difference in survival between SBRT+ADT and standard of care EBRT+ADT for UIR or HR PC. These results support recent NCCN guideline updates, which include SBRT as a nonpreferred option for higher risk men. Prospective validation would further strengthen the evidence basis behind these recommendations.
\end{abstract}

Keywords: Ultrahypofractionation, Prostate cancer, High risk

\section{Introduction}

Hypofractionated radiation therapy for prostate cancer is an appealing and increasingly adopted approach that has advantages from a radiobiologic, cost, and patient convenience standpoint [1-4]. Non-inferiority phase 3 randomized trials have confirmed the safety and efficacy of moderate hypofractionation (2.5-3 Gy per fraction) compared to conventional fractionation $(1.8-2$ Gy per fraction) [5-7]. Furthermore, one randomized trial showed superior biochemical control with moderate hypofractionation compared to conventional fractionation [8]. Moderate hypofractionation has now been accepted as a standard-of-care across all risk groups and a preferred regimen in ASTRO and NCCN Guidelines $[9,10]$.

More recent randomized trials have shown that ultrahypofractionated radiation ( $\leq 7$ fractions, $\geq 5$ Gy per fraction), or stereotactic body radiation (SBRT) when delivered in $\leq 5$ fractions with image/stereotactic guidance, is non-inferior to conventional fractionation for tumor control and toxicity, and to moderate hypofractionation for toxicity $[11,12]$. There is increasing interest in ultrahypofractionated radiation therapy for prostate cancer to further optimize patient convenience and cost effectiveness [13]. The ASTRO/ASCO/AUA societal guidelines do not currently recommend routine use of ultrahypofractionated radiation therapy for men with unfavorable risk prostate cancer, with a conditional recommendation against its use in men with high risk disease [9]. Since publication of those guidelines, however, the HYPO-RT-PC randomized trial [11] showed noninferiority of ultrahypofractionation in a cohort of intermediate and high risk men. However, androgen deprivation therapy (ADT), which is standard in the United States in these men, was not permitted in that trial. Furthermore, only $11 \%$ of enrolled men on that trial had NCCN-defined high risk disease. How ultrahypofractionation plus ADT compares with conventional/ moderate fractionation plus ADT in men with higher risk prostate cancer remains unknown. Herein, we examine outcomes between these two approaches in men with UIR and HR prostate cancer who receive concomitant ADT. We hypothesize that ultrahypofractionation has similar outcomes as conventional/moderate fractionation for these men.

\section{Methods}

Men > 40 years with localized prostate cancer treated with external radiation and ADT with curative intent between 2004 and 2016 were analyzed from the National Cancer Database. Patients who received brachytherapy, surgery, chemotherapy, or immunotherapy were excluded. Patients missing ADT or risk stratification data were excluded. Those that received ADT $>180$ days before or after the start of radiation were excluded. Ultrahypofractionation (SBRT) was defined as 5 fractions of $\geq 5$ Gy per fraction and conventional/moderate fractionation (EBRT) as $\leq 3$ Gy per fraction and total dose $\geq 60$ Gy. Patients were stratified by risk using NCCN criteria: unfavorable intermediate (UIR) and high (HIR). ${ }^{1}$ ANOVA and chi square test was used to compare patient/demographic characteristics. Cochran-Armitage test for trend was used to evaluate utilization of SBRT in this cohort between 2004 and 2016. Kaplan Meier and multivariable Cox proportional hazards were used to compare overall survival (OS) between those who received EBRT versus SBRT, accounting for age, race, comorbidity index, and year of diagnosis. All analyses were computed using SAS 9.4 (SAS Institute Inc., Cary, NC). Tests were 2-sided with a 0.05 level of significance. This study received IRB exemption.

\section{Results}

Forty-one thousand three hundred fifty-five men were eligible for this analysis: 40,797 treated with EBRT and 558 treated with SBRT (Table 1). Although SBRT has been minimally utilized in UIR and HIR prostate cancer between 2004 and 2016, there has been a significant rise in its use over this time ( $p$ for trend $<.001$ ). There was an uptick in use of SBRT in UIR men after 2011-2012 (Supplemental Figure). A larger proportion of men in the SBRT cohort were Black, treated at an academic center, had median household incomes $\geq \$ 46,000$, were treated in the Northeast and West United States, lived > 
Table 1 Patient clinical and demographic characteristics

\begin{tabular}{|c|c|c|c|c|c|}
\hline \multirow[t]{2}{*}{ Covariate } & \multirow[t]{2}{*}{ Statistics } & \multirow[t]{2}{*}{ Level } & \multicolumn{2}{|c|}{ Radiation group } & \multirow{2}{*}{$\begin{array}{l}\text { Parametric } \\
P \text {-value }\end{array}$} \\
\hline & & & SBRT $N=558$ & EBRT $N=40,797$ & \\
\hline \multirow[t]{3}{*}{ Race } & $\mathrm{N}(\mathrm{Col} \%)$ & White & $415(75.73)$ & $32,076(79.47)$ & 0.07 \\
\hline & N (Col \%) & Black & $114(20.8)$ & $6923(17.15)$ & \\
\hline & N (Col \%) & Other & $19(3.47)$ & $1363(3.38)$ & \\
\hline \multirow[t]{2}{*}{ Facility Type } & N (Col \%) & Non-academic program & $237(42.47)$ & $28,382(69.57)$ & $<.001$ \\
\hline & N (Col \%) & Academic program & $321(57.53)$ & $12,415(30.43)$ & \\
\hline \multirow[t]{4}{*}{ Median Income Quartiles } & N (Col \%) & $<\$ 30,000$ & $76(14.07)$ & $5527(13.96)$ & $<.001$ \\
\hline & N (Col \%) & $\$ 30,000-\$ 34,999$ & $60(11.11)$ & $7315(18.47)$ & \\
\hline & N (Col \%) & $\$ 35,000-\$ 45,999$ & $130(24.07)$ & $11,117(28.07)$ & \\
\hline & N (Col \%) & $>=\$ 46,000$ & $274(50.74)$ & $15,643(39.5)$ & \\
\hline \multirow[t]{4}{*}{ Year of diagnosis } & N (Col \%) & 2004-06 & $92(16.49)$ & 8811 (21.6) & $<.001 \wedge$ \\
\hline & N (Col \%) & 2007-09 & $109(19.53)$ & $9121(22.36)$ & \\
\hline & N (Col \%) & 2010-12 & $127(22.76)$ & $10,852(26.6)$ & \\
\hline & N (Col \%) & 2013-15 & $230(41.22)$ & $12,013(29.45)$ & \\
\hline \multirow[t]{3}{*}{ Insurance status } & N (Col \%) & Not Insured & $12(2.2)$ & $744(1.85)$ & 0.787 \\
\hline & N (Col \%) & Private & $146(26.79)$ & $10,563(26.25)$ & \\
\hline & N (Col \%) & Government insurance & $387(71.01)$ & $28,931(71.9)$ & \\
\hline \multirow[t]{4}{*}{ Facility Location } & N (Col \%) & Northeast & $188(33.69)$ & $10,369(25.42)$ & $<.001$ \\
\hline & N (Col \%) & South & $155(27.78)$ & $13,291(32.58)$ & \\
\hline & N (Col \%) & Midwest & $112(20.07)$ & $10,751(26.35)$ & \\
\hline & N (Col \%) & West & $103(18.46)$ & $6386(15.65)$ & \\
\hline \multirow[t]{2}{*}{ Risk group } & N (Col \%) & Unfavorable intermediate & $130(23.3)$ & $5094(12.49)$ & $<.001$ \\
\hline & N (Col \%) & High & $428(76.7)$ & $35,703(87.51)$ & \\
\hline \multirow[t]{3}{*}{ Distance to facility } & N (Col \%) & 0-10 miles & $250(44.88)$ & $22,460(55.25)$ & $<.001$ \\
\hline & N (Col \%) & $10-50$ miles & $212(38.06)$ & $15,550(38.25)$ & \\
\hline & N (Col \%) & $50+$ miles & $95(17.06)$ & $2641(6.5)$ & \\
\hline \multirow[t]{3}{*}{ Charlson comorbidity score } & N (Col \%) & 0 & $472(84.59)$ & $34,616(84.85)$ & 0.197 \\
\hline & N (Col \%) & 1 & $74(13.26)$ & $4825(11.83)$ & \\
\hline & N (Col \%) & $2+$ & $12(2.15)$ & $1356(3.32)$ & \\
\hline \multirow[t]{3}{*}{ Urban/Rural Location } & $\mathrm{N}(\mathrm{Col} \%)$ & Metro & $439(82.06)$ & $31,912(80.12)$ & 0.022 \\
\hline & N (Col \%) & Urban & $92(17.2)$ & $6854(17.21)$ & \\
\hline & N (Col \%) & Rural & $4(0.75)$ & $1064(2.67)$ & \\
\hline \multirow[t]{6}{*}{ Age at Diagnosis } & $\mathrm{N}$ & & 558 & 40,797 & 0.980 \\
\hline & Mean & & 70.18 & 70.19 & \\
\hline & Median & & 71 & 71 & \\
\hline & Min & & 43 & 40 & \\
\hline & Max & & 90 & 90 & \\
\hline & Std Dev & & 7.95 & 7.91 & \\
\hline
\end{tabular}

\footnotetext{
a Parametric $p$-value calculated by ANOVA for numerical covariates and chi-square test for categorical covariates
}

$\wedge P$-value calculated by Cochran-Armitage test for trend

50 miles away from treatment facility, and resided in metro/urban over rural areas (Table 1).

The median follow up time was 74 months. There was no difference in estimated 6-year OS between men treated with SBRT versus EBRT regardless of risk group
(SBRT versus EBRT, UIR: 93.3\% versus 90.9\%, log-rank $p=.40$, Fig. 1a; HIR: $80.8 \%$ versus $80.4 \%, \log$-rank $p=$ .21 , Fig. 1b). On multivariable analysis, accounting for age, race, and comorbidity, there was no difference in mortality for men treated with SBRT compared to EBRT (UIR: 


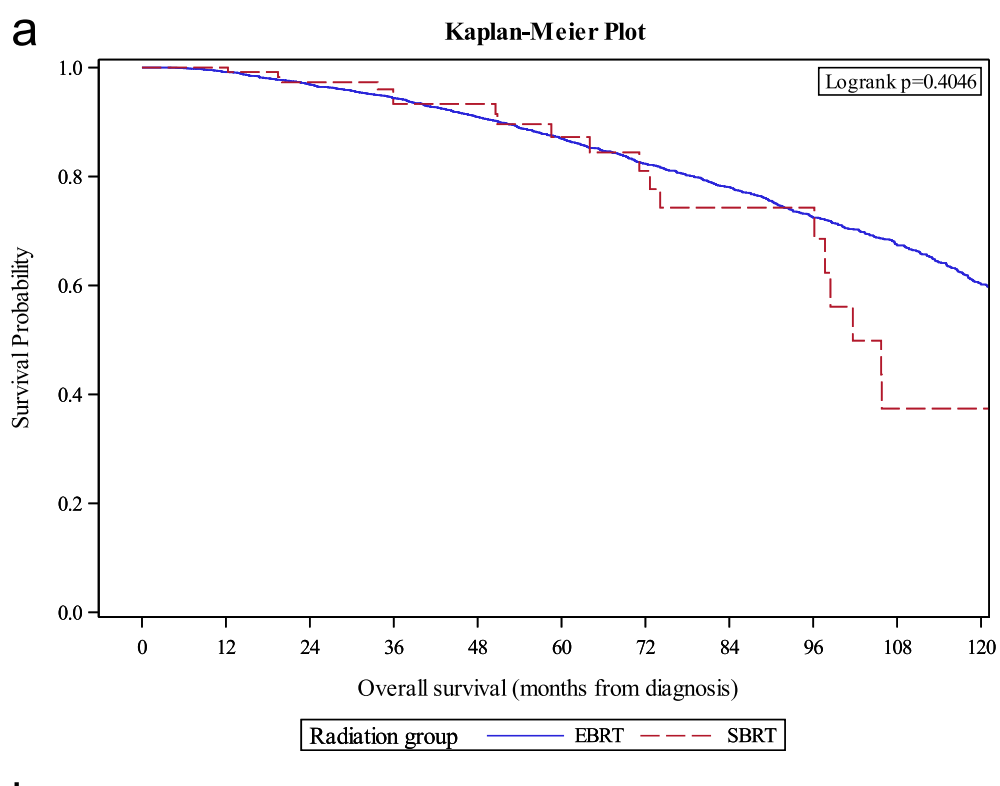

b

Kaplan-Meier Plot

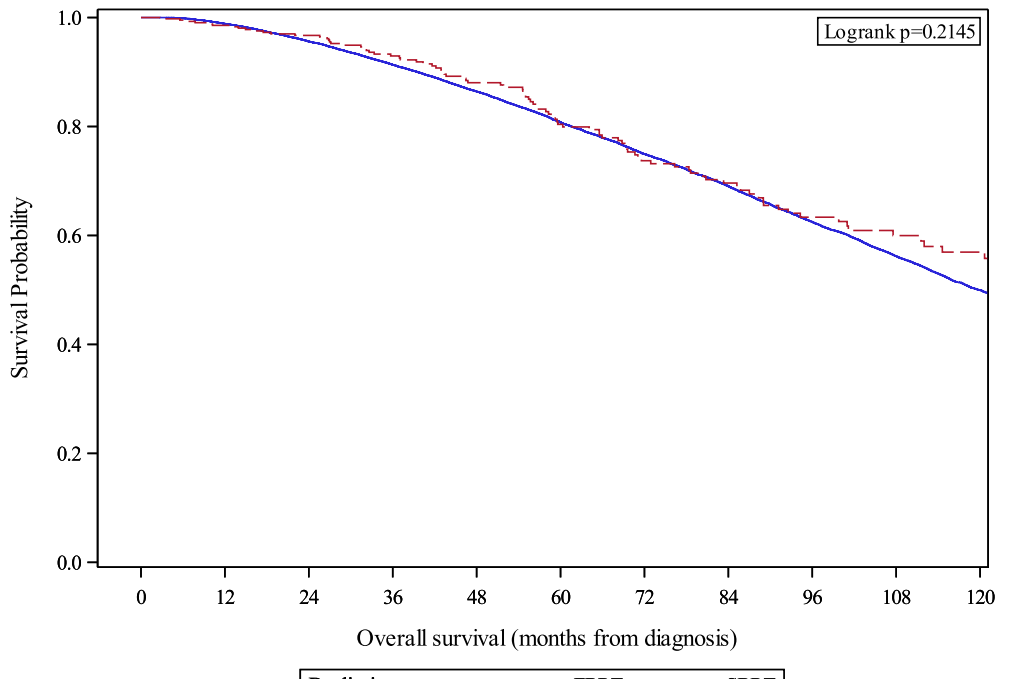

Radiation group - EBRT --- SBRT

Fig. 1 Kaplan-Meier survival estimates between EBRT and SBRT for unfavorable intermediate (a) and high (b) risk prostate cancer

adjusted HR 1.09, 95\% CI 0.68-1.74, $p=.72$; HIR: adjusted HR 0.93 , 95\% CI $0.76-1.14, p=.51$ ). On sensitivity analyses, when 1) excluding SBRT < 7 Gy per fraction, 2) excluding EBRT $<74$ Gy if $<2$ Gy per fraction, 3) limiting the cohort to $<65$ years of age, and 4) limiting the cohort to those with no medical comorbidities, no significant difference in OS was found between SBRT and EBRT (Table 2).

\section{Discussion}

We found no difference in survival between SBRT+ADT and standard of care EBRT+ADT for UIR or HIR PC. ASTRO/ASCO/AUA consensus guidelines, though outdated, do not recommend routine use of SBRT for higher risk prostate cancer. Conversely, recent NCCN guidelines provide support of SBRT for UIR and HIR patients, particularly when more protracted courses may provide social or medical hardship [10]. The NCCN note that moderate fractionation is the preferred external beam radiation therapy regimen for all risk categories. Our results reinforce the NCCN's recent decision to endorse SBRT as an option for men with higher risk prostate cancer and may motivate ASTRO to reconsider their guidelines.

More widespread SBRT use in these patients may be appropriate after publication of the HYPO-RT-PC trial that showed non-inferiority of ultrahypofractionation compared to conventional fractionation after a median 
Table 2 Multivariable overall survival (OS) analysis between SBRT+ADT versus EBRT+ADT (referent) in overall cohort and select subgroups for unfavorable intermediate (a) and high (b) risk prostate cancer

\begin{tabular}{|c|c|c|c|}
\hline & HR & $95 \% \mathrm{Cl}$ & $p$ \\
\hline \multicolumn{4}{|l|}{ a. Unfavorable Intermediate Risk } \\
\hline Overall & 1.09 & $0.68-1.74$ & .72 \\
\hline \multicolumn{4}{|l|}{ Subgroup Analyses } \\
\hline Excluding any SBRT $<7$ Gy per fraction & 1.15 & $0.72-1.83$ & .57 \\
\hline Excluding any EBRT $<2$ Gy per fraction and $<74$ Gy total dose & 1.24 & $0.79-1.96$ & .35 \\
\hline Excluding Charlson Deyo $\geq 1$ & 1.29 & $0.89-1.34$ & .33 \\
\hline Excluding age $\geq 65$ & 1.13 & $0.86-1.36$ & 60 \\
\hline \multicolumn{4}{|l|}{ b. High Risk } \\
\hline Overall & 0.93 & $0.76-1.14$ & .51 \\
\hline \multicolumn{4}{|l|}{ Subgroup Analyses } \\
\hline Excluding SBRT if $<7$ Gy per fraction & 0.92 & $0.74-1.14$ & .44 \\
\hline Excluding EBRT if $<2$ Gy per fraction and $<74$ Gy total dose & 0.90 & $0.74-1.10$ & .30 \\
\hline Excluding Charlson Deyo $\geq 1$ & 0.83 & $0.66-1.03$ & .10 \\
\hline Excluding age $\geq 65$ & 0.72 & $0.44-1.17$ & .18 \\
\hline
\end{tabular}

follow up of 5 years. ADT use, which is standard for these patients in the United States, was not permitted in that study. Prospective data regarding SBRT with concomitant ADT is lacking; data showing favorable outcomes with SBRT, though with inconsistent ADT use, for higher risk prostate cancer is largely retrospective [14]. Our study corroborates institutional results regarding comparable disease control and survival with SBRT compared to conventional/moderate hypofractionation.

There are several potential advantages of SBRT. For one, the alpha-beta ratio of prostate cancer may potentially be lower than for late normal tissue reactions [15]. If true, ultrahypofractionation could increase the therapeutic ratio and thereby offer more efficacious local therapy. Second, despite the use of complex immobilization, on-board imaging, and physics resources, SBRT reduces overall costs to payers and patients, with up to half the cost per allowable Medicare fee schedules, largely due to its abbreviated treatment schedule $[16,17]$. In an era of rising healthcare costs, as well as anticipated Alternative Payment Models with bundled fee schedules, providers will be incentivized to utilize the most cost-effective options. Finally, with reduced treatment visits, SBRT provides a more convenient treatment option for patients compared to protracted fractionation schemes.

Based on recently available level one evidence published in 2019, specifically PACE-B and HYPO-RT-PC, SBRT should be more widely accepted as an appropriate regimen for $\mathrm{PC}$ in patients eligible for prostate $+/-$ seminal vesicle treatment alone, regardless of risk group. This is relevant in an era of optimal locoregional imaging, namely MRI, which can help rule out high risk features that may otherwise support larger treatment margins and/or pelvic nodal irradiation. Even for patients who may require pelvic nodal treatment, however, the SATURN trial has shown safety and promising efficacy of elective nodal irradiation utilizing ultrahypofractionation [18]. For PC there is a radiobiologic advantage of ultrahypofractionation over protracted courses utilizing smaller doses per treatment. Now, there is prospective basis for its use.

One concern that may limit utilization of SBRT for localized prostate cancer is toxicity. The HYPO-RT-PC trial [11] showed higher patient-reported urinary and bowel toxicity with ultrahypofractionation, with higher urinary toxicity extending to 1 year after completion of treatment; late toxicity, however, was similar between ultrahypofractionation and conventional fractionation. PACE-B [12], on the other hand, showed non-inferior toxicity within the first 12 weeks after treatment between SBRT and conventional/moderate fractionation for favorable risk prostate cancer. The discrepancy in acute toxicity between these two studies may be due to the time frame of each trial accrual, with patients enrolled on HYPO-RT-PC treated between 2005 and 2015 and those enrolled on PACE-B treated between 2012 and 2018. Approximately $80 \%$ of men on HYPO-RT-PC received 3-dimensional conformal RT; advancements in treatment delivery, including intensity modulation, between these two eras may explain the discrepancy in acute toxicity findings [19]. Furthermore, recent multiinstitutional analysis of prospectively-collected data of over 2000 men treated with SBRT showed very low rates of grade 3 genitourinary and gastrointestinal toxicity after 7 years of follow up [20]. Integration of rectal 
spacer or balloon, as allowed in the NRG GU005 phase 3 trial, may lower toxicity even further. Whether the addition of androgen deprivation therapy, postulated to function as least partly through radiosensitization [21], may increase acute/late toxicities when delivered with SBRT is unknown and remains subject for future analysis; however, based on similar toxicity seen between moderate and conventional fractionation when delivered with concomitant ADT [4-6], this likelihood is low.

This analysis has several limitations. First, given the retrospective design using a population-based database, analyses are subject to selection biases and imbalances in unmeasured variables. However, multivariate modeling was utilized to address potential confounding. Furthermore, we completed stringent sensitivity analyses confining the cohort to those treated with modern-day doses, as well as excluding older and comorbid patients, with consistent results. Second, outcome measures in the NCDB are limited to OS, so details regarding biochemical control and toxicity unavailable. While we believe OS is a primary outcome of measure in these higher risk patients to influence management decisions, several of these unavailable data are relevant in this cohort given that treatment decisions often consider patient quality of life.

\section{Conclusion}

In conclusion, we found no difference in survival between SBRT+ADT and standard of care EBRT+ADT for UIR or HIR PC. SBRT offers a cost-effective, convenient option for prostate cancer patients in centers that are able to deliver safe therapy with precise, image-guided techniques. SBRT has wide guideline support for low and favorable intermediate risk prostate cancer. For UIR and HIR prostate cancer, however, there is historically low utilization and reserved support for SBRT use, with conditional recommendation against its use by ASTRO/ ASCO/AUA task force. HYPO-RT-PC trial provides level one support for SBRT for unfavorable intermediate and high risk prostate cancer, but ADT was not permitted in that study. How SBRT plus ADT compares against conventional/moderate fractionated EBRT plus ADT is unknown, but our results suggest that long-term outcomes may not differ. These findings are concordant with the updated NCCN guidelines, which list SBRT as an option in men with higher risk disease.

\section{Supplementary information}

Supplementary information accompanies this paper at https://doi.org/10. 1186/s13014-020-01658-5.

Additional file 1 Supplemental Figure. Utilization of standard or moderately hypofractionated radiation (EBRT) versus

ultrahypofractionated radiation (SBRT) in men with unfavorable intermediate (a) and high (b) risk prostate cancer receiving androgen deprivation therapy.

\section{Acknowledgements}

Not applicable.

Authors' contributions

SP and TJ oversaw the conception and design of the study. JS and CZ oversaw the statistical analysis of the database. SP, JS, CZ, BFV, TJ analyzed and interpreted the patient data. $\mathrm{BR}, \mathrm{RC}$, and $\mathrm{AJ}$ made substantial revisions to the manuscript. All authors read and approved the final manuscript.

\section{Funding}

Research was supported in part by the Biostatistics and Bioinformatics Shared Resource of Winship Cancer Institute of Emory University and NIH/ $\mathrm{NCl}$ under award number P30CA138292. The content is solely the responsibility of the authors and does not necessarily represent the official views of the National Institutes of Health.

Availability of data and materials

Research data are available in the National Cancer Database via Common on Cancer accredited facilities.

Ethics approval and consent to participate

Institutional review board approval was waived for this de-identified, population-based database.

Consent for publication

Not applicable.

\section{Competing interests}

Chen: Consulting or Advisory Role with Medivation/Astellas, Accuray, Bayer, Blue Earth Diagnostics. Research Funding with Accuray. Jani: Consulting or Advisory Role with Blue Earth Diagnostics.

\section{Author details}

${ }^{1}$ Department of Radiation Oncology, Winship Cancer Institute, Emory University, Atlanta, GA, USA. ${ }^{2}$ Department of Biostatistics and Bioinformatics, Emory University, Atlanta, GA, USA. ${ }^{3}$ Department of Radiation Medicine and Applied Sciences, University of California San Diego, San Diego, CA, USA. ${ }^{4}$ Department of Radiation Oncology, University of Kansas, Kansas City, KS, USA. ${ }^{5}$ Department of Radiation Oncology, University of North Carolina, Chapel Hill, NC, USA.

Received: 18 July 2020 Accepted: 31 August 2020

Published online: 15 September 2020

References

1. Brenner DJ, Hall EJ. Fractionation and protraction for radiotherapy of prostate carcinoma. Int J Radiat Oncol Biol Phys. 1999;43:1095-101.

2. Fowler J, Chappell R, Ritter M. Is a/B for prostat tumors really low? Int J Radiat Oncol Biol Phys. 2001;50:1021-31.

3. Bentzen SM, Ritter MA. The a/ $\beta$ ratio for prostate cancer: what is it, really? Radiother Oncol. 2005:76:1-3.

4. Zemplenyi AT, Kalo Z, Kovacs G, et al. Cost-effectiveness analysis of intensity-modulated radiation therapy with normal and hypofrationated schemes for treatment of localized prostate cancer. Eur J Cancer Care (Engl). 2018:27:e12430.

5. Dearnaley D, Syndikus I, Mossop H, et al. Conventional versus hypofractionated high-dose intensity modulated radiotherapy for prostate cancer: 5-year outcomes of the randomised, non-inferiority, phae $3 \mathrm{CHHiP}$ trial. Lancet Oncol. 2016;17:1047-60.

6. Lee WR, Dignam JJ, Amin MB, et al. Randomized phase 3 noninferiority study comparing two radiotherapy fractionation schedules in patients with low-risk prostate cancer. J Clin Oncol. 2016:34:2325-32.

7. Catton CN, Lukka H, Gu CS, et al. Randomized trial of a hypofractionated radiation regimen for the treatment of localized prostate cancer. J Clin Oncol. 2017:35:1884-90.

8. Hoffman KE, Voong KR, Levy LB, et al. Randomized trial of hypofractionated, dose-escalated, intensity-modulated radiation therapy (IMRT) versus 
conventionally fractionated IMRT for localized prostate cancer. J Clin Oncol. 2018;36:2943-9.

9. Morgan SC, Hoffman K, Loblaw DA, et al. Hypofractionated radiation therapy for localized prostate cancer: executive summary of an ASTRO, ASCO, and AUA evidence-based guideline. Pract Radiat Oncol. 2018;8:35460.

10. National Comprehensive Cancer Network. Prostate Cancer (NCCN Guidelines Verson 3.2020). 2020. https://www.nccn.org/professionals/ physician_gls/pdf/prostate.pdf.

11. Widmark A, Gunnlaugsson A, Beckman L, et al. Ultra-hypofractionated versus conventionally fractionated radiotherapy for prostate cancer: 5 -year outcomes of the HYPO-RT-PC randomised, non-inferiority, phase 3 trial. Lancet. 2019;394(10196):385-95. https://doi.org/10.1016/s01406736(19)31131-6.

12. Brand DH, Tree AC, Ostler $\mathrm{P}$, et al. Intensity-modulated fractionated radiotherapy versus stereotactic body radiotherapy for prostate cancer (PACE-B): acute toxicity findings from an international, randomised, openlabel, phase 3, non-inferiority trial. Lancet Oncol. 2019;20(11):1531-43. https://doi.org/10.1016/S1470-2045(19)30569-8.

13. King CR, Freeman D, Kaplan I, et al. Stereotactic body radiotherapy for localized prostate cancer: pooled analysis from a multi-institutional consortium of prospective phase II trials. Radiat Oncol. 2013;109:217-21.

14. Dasu A, Toma-Dasu I. Prostate alpha/beta revisited - an analysis of clinical results from 14,168 patients. Acta Oncol. 2012;51:963-74.

15. Pan $\mathrm{HY}$, Jiang J, Hoffman $\mathrm{KE}$, et al. Comparative toxicities and cost of intensity-modulated radiotherapy, proton radiation, and stereotactic body radiotherapy among younger men with prostate cancer. J Clin Oncol. 2018; 36(18):1823-30.

16. Hodges JC, Lotan Y, Boike TP, et al. Cost-effectiveness analysis of stereotactic body radiation therapy versus intensity-modulated radiation therapy: an emerging initial radiation treatment option for organ-confined prostate cancer. J Oncol Pract. 2012;8(3 Suppl):e31s-7s.

17. Mitin T, Henry A, Choudhury A, et al. SBRT for localized prostate cancer: is it ready for take-off? Int J Radiat Oncol Biol Phys. 2019;105(3):618-20.

18. Alayed $Y$, Cheung $P$, Vesprini $D$, et al. SABR in high-rise prostate Cancer: outcomes from 2 prospective clinical trials with and without elective nodal irradiation. Int J Radiat Oncol Bio Phys. 2019;104(1):36-41.

19. Michalski JM, Yan Y, Watkins-Bruner D, et al. Preliminary toxicity analysis of 3-dimensional conformal radiation therapy versus intensity modulated radiation thearpy on the high-dose arm of the radiation therapy oncology group 0126 prostate cancer trial. Int J Radiat Oncol Biol Phys. 2013;87:932-8

20. Kishan AU, Dang A, Katz AJ, et al. Long-term outcomes of stereotactic body radiotherapy for low-risk and intermediate-risk prostate Cancer. JAMA Netw Open. 2019;2(2):e188006. https://doi.org/10.1001/jamanetworkopen.2018. 8006.

21. Polkinghorn WR, Parker JS, Lee MX, et al. Androgen receptor signaling regulates DNA repair in prostate cancers. Cancer Discov. 2013;3:1245-53.

\section{Publisher's Note}

Springer Nature remains neutral with regard to jurisdictional claims in published maps and institutional affiliations.

Ready to submit your research? Choose BMC and benefit from:

- fast, convenient online submission

- thorough peer review by experienced researchers in your field

- rapid publication on acceptance

- support for research data, including large and complex data types

- gold Open Access which fosters wider collaboration and increased citations

- maximum visibility for your research: over $100 \mathrm{M}$ website views per year

At $\mathrm{BMC}$, research is always in progress.

Learn more biomedcentral.com/submissions 